\title{
O PRINCÍPIO DA PRECAUÇÃO E O PRINCÍPIO DE RESPONSABILIDADE DE HANS JONAS
}

\author{
Ricardo Libel Waldman ${ }^{1}$ \\ Vanessa Bueno Sampaio ${ }^{2}$ \\ Marcelo Giovanni Vargas Munhoz ${ }^{3}$
}

\section{Resumo}

Este trabalho tem por objetivo demonstrar que a concepção ética de responsabilidade de Hans Jonas pode justificar o princípio da precaução ambiental. É papel do ser humano garantir e assegurar condições de vida para a presente e futuras gerações humanas e também para todas as espécies de vida na Terra. A aplicação do princípio da precaução como demanda ético-jurídica, exige a adaptação dos valores e concepções morais da sociedade visando justamente isso. $\mathrm{O}$ artigo expõe a necessidade de repensar a aplicação do princípio da precaução em conformidade com essa nova visão de responsabilidade. Para tanto, o artigo parte do resultado de estudos teóricos de cunho qualitativo a respeito do princípio da precaução e dos trabalhos de Hans Jonas. A referência teórica será a obra do autor "O Princípio da Responsabilidade: ensaio de uma ética para a civilização tecnológica" escrita no final do século XX. O artigo nos leva à conclusão de que Hans Jonas ultrapassa o subjetivismo dos valores morais e nos faz repensar sobre a responsabilidade do ser humano sobre a Terra. O princípio da precaução é visto como forma de orientação de um agir de modo responsável, consciente e sustentável. Há, portanto, uma possibilidade de conexão entre o princípio da precaução e os fundamentos filosóficos de cunho ético e moral ora apresentados.

Palavras-chave: Precaução; Meio Ambiente; Sustentabilidade; Responsabilidade; Ética.

\section{INTRODUÇÃO}

O presente artigo pretende relacionar a ética da responsabilidade de Hans Jonas ao princípio da precaução do Direito Ambiental, a fim de demonstrar que o verdadeiro sentido da de tal medida envolve, principalmente, demandas éticas. Isso se faz necessário haja vista que os riscos de danos decorrentes da atividade humana sobre as quais não há conhecimento científico consensual com relação a sua segurança podem ser incalculáveis.

\footnotetext{
${ }^{1}$ Doutor em Direito pela Universidade Federal do Rio Grande do Sul; Professor Assistente da Pontifícia Universidade Católica do Rio Grande do Sul e Professor Adjunto no Centro Universitário Ritter dos Reis. E-mail: ricardolibelwaldman@yahoo.com

${ }^{2}$ Pós-Graduada em Direito Público pela Universidade Cândido Mendes, Pós-Graduada em Direito Notarial e Registral na Universidade Anhanguera- UNIDERP, Mestranda em Direitos Humanos no Centro Universitário Ritter dos Reis. Escrivã Responsável pelo Registro Civil de Pessoas Naturais de Maracajá -SC.E-mail: vanessa_bueno@hotmail.com

${ }_{3}^{3}$ Pós-Graduando em Docência do Ensino Superior pelo Instituto Estadual do Rio Grande do Sul - IERGS, Mestrando em Direito Humanos no Centro Universitário Ritter dos Reis. Advogado Empresarial. E-mail: marcelo.munhoz@embratec.com.br
} vol.10, nº. 01, Rio de Janeiro, 2017.pp. 199-218 
A escolha do princípio da precaução como objeto de estudo decorre do fato de vivermos em uma civilização tecnológica, na qual a ciência e a tecnologia estão constantemente criando novos produtos, serviços e processos, os quais, por sua vez geram riscos para a coletividade, riscos esses que não podem ser conhecidos na sua totalidade. Tal princípio é relevante para esta realidade porque ele estabelece que o Estado deve intervir sempre que houver risco de um dano grave, ainda que não exista certeza científica a respeito de tal risco ou dano. Tal norma se diferencia do princípio da prevenção na medida em que este determina medidas contra atividades e produtos com relação aos quais existe conhecimento científico consolidado.

O princípio da precaução, embora já devidamente reconhecido em Tratados Internacionais, no direito interno de diversos países, inclusive do Brasil, tem na sua densificação normativa um relevante desafio para o jurista. Isto, pois, ao mesmo tempo em que ele potencialmente serve de base para a tutela do direito humano ao meio ambiente ecologicamente equilibrado em aspectos importantes como a regulação da inovação, seus pressupostos e fundamentos são bastante imprecisos, como se demonstrará mais adiante. A proposta deste artigo é aprofundar a discussão sobre como houve a construção destes pressupostos e fundamentos com base no Princípio Responsabilidade de Hans Jonas.

Hans Jonas, filósofo judeu, nasceu na Alemanha em 1903 e faleceu nos EUA em fevereiro de 1993. É considerado uma das grandes referências da ética contemporânea e tem como principal proposta um "novo agir humano", fundamentado na responsabilidade frente ao progresso técnico - científico e suas consequências.

Este artigo toma como referência teórica a principal obra do autor "O Princípio Responsabilidade: ensaio de uma ética para a civilização tecnológica" escrita no final do século XX, em alemão em 1970 e em inglês em 1984. O livro tem como ponto focal a busca de um fundamento ético para um dever de possibilitar a sobrevivência física e espiritual da humanidade.

Hans Jonas (2006, p. 48) nos faz repensar sobre os rumos éticos e os valores que as civilizações tecnológicas têm adotado. Apresenta um novo postulado ético, em contrapartida ao tradicional postulado de Kant. Segundo ele, o princípio moral supremo é: atua de tal forma que os efeitos de suas ações sejam compatíveis com o futuro homem na Terra. Conforme o autor, o desenvolvimento tecnológico e científico chegou a tal ponto que devemos controlar seus efeitos na biosfera. Nosso papel para a sobrevivência do ser humano no mundo depende de como vivemos e de como asseguramos que as futuras gerações também tenham condições de vida. Nesse sentido, a responsabilidade ética implica na noção de que os indivíduos são moralmente responsáveis por suas escolhas. A base do princípio da precaução é aceitar essa responsabilidade, com uma visão moral que abrange a coletividade presente e futura, diferentemente da ética individualista tradicional.

$\mathrm{Na}$ visão de Hans Jonas, a razão, no seu discurso ético, volta-se para um agir coletivo, sugerindo a solidariedade humana no sentido de um meio ambiente equilibrado. A incerteza da vida futura é resultado de um equívoco cometido pelo homem ao se isolar da natureza. Porém, esse desvio pode ser consertado por meio da vol.10, nº. 01, Rio de Janeiro, 2017.pp. 199-218 
responsabilidade e da mudança de valores da sociedade. Essa evolução ética e social é conquistada pela educação e pela aceitação da responsabilidade direcionada à preservação da humanidade. Assim, o princípio da precaução deve ser interpretado em um sentido forte segundo o qual cabe ao Estado e à Sociedade provar que um produto, procedimento ou empreendimento é compatível com a manutenção da vida na Terra.

A primeira parte do artigo tem por propósito demonstrar os aspectos históricos e o conceito jurídico do princípio da precaução. O capítulo introduz os conceitos básicos do princípio e expõe a necessidade de uma evolução conceitual e epistemológica da precaução.

A segunda e terceira partes do presente texto relacionam o princípio da responsabilidade de Hans Jonas à precaução ambiental. Explicam a necessidade da responsabilidade como cerne da ética a qual ganha magnitude em função do desenvolvimento tecnológico, pois tal desenvolvimento põe em risco, o fim (enquanto finalidade) e o valor, de que tudo há na Terra.

\section{O PRINCÍPIO DA PRECAUÇÃO}

A palavra precaução vem do Latim precautio-onis que significa "cautela antecipada; prevenção"(MICHAELIS, 2015). Segundo Milaré, é substantivo do verbo precaver-se ( $p r a e=$ antes e cavere= tomar cuidado) e sugere cuidados antecipados com o desconhecido, cautela nas ações ou omissões (MILARÉ, 2009, p. 96).

A ideia de precaução no mundo é antiga, vem concebida na essência do homem que, via de regra, tende a preferir não perder algo ao invés de arriscar o que tem para ganhar. Além da aversão às perdas, Sunstein (2003, p. 1013) explica que o mito da natureza benevolente também fortalece a utilização da precaução. A sociedade tende a considerar que tudo que acontece de ruim na natureza é resultado da influência humana.

Na medicina do século XIX, a precaução era usada nas ocasiões de incertezas científicas. Ao longo da história o princípio ganhou forças, sobretudo fora da área do direito. (LORENZETTI, 2010, p. 75). No Direito Ambiental, o princípio da precaução tem origem nas tradições alemãs, dentro do conceito da democracia social da década de 1930 com a concepção da boa gestão doméstica. Significava a necessidade de uma política de cooperação entre os indivíduos, a economia e o Estado, na busca de melhorias para a sociedade e sua convivência harmônica com a natureza. A utilização do termo alemão Vorsorgegebot, é feita em um sentido amplo, que envolve as noções de riscos de prevenção, custos-benefícios, cenários econômicos e responsabilidades éticas (O’RIORDAN, 1994, p. 16). Nesse contexto, o princípio da precaução é visto como um modo do Estado intervir na economia, na tecnologia e na moral, a fim de planejar um bom governo. Segundo Bosselman, o princípio é tido até hoje como o mais importante das políticas ambientais alemãs (BOSSELMANN, 2008, p. 60).

A partir da década de 1970, a visão alemã da precaução se espalhou pelo mundo e o princípio passou a 
ser cada vez mais conhecido e utilizado internacionalmente. Em 1982, na Convenção sobre o Direito do Mar e em 1987, e na Segunda Conferência Internacional do Mar Norte, já se evidencia o caráter precaucional. Com a Declaração do Rio sobre o Meio Ambiente em 1992, o princípio assume expressamente seu papel no direito ambiental internacional, arrolado como princípio 15 da Declaração, com o seguinte conceito:

Com o fim de proteger o meio ambiente, o princípio da precaução deverá ser amplamente observado pelos Estados, de acordo com suas capacidades. Quando houver ameaça de danos graves ou irreversíveis, a ausência de certeza científica absoluta não será utilizada como razão para o adiamento de medidas economicamente viáveis para prevenir a degradação ambiental (CONFERÊNCIA DAS NAÇÕES UNIDAS SOBRE O MEIO AMBIENTE, 1992). (Grifo nosso)

O princípio ainda foi adotado na década de 1990 na Convenção de Bamako, sobre a proibição de importar dejetos perigosos e controlar movimentos transfronteiriços na África. Em 1992, foi incluído na Convenção sobre a Proteção e Utilização dos Cursos d'água Transfronteiriços e de Lagos Internacionais, na Convenção sobre a Diversidade Biológica; bem como na Convenção sobre Mudanças Climáticas e, posteriormente, em diversas outras convenções e tratados assinados no mundo (LORENZETTI, 2010, p. 75).

Pela importância que assume, vale descrever com mais detalhes a regulamentação do princípio da precaução na União Europeia. Desde o Tratado de Maastricht, a política ambiental europeia deve se dar de acordo com o princípio da precaução. Determinou-se que a ausência de comprovação do nexo causal entre determinada atividade e um dano ambiental não pode, por si só, impedir medidas preventivas: in dubio pro natura (JANS; VEDDER, 2008, p. 37-38).

A Comissão Europeia adotou, em 2000, uma Comunicação em que interpreta o referido princípio (ARAGÃO, 2008, p.10). Esta Comunicação considera que o princípio da precaução diz respeito ao gerenciamento do risco, o que não significa risco zero. (JANS; VEDDER, 2008, p. 38). Ainda, a jurisprudência da Corte de Justiça Europeia considera que, apesar do princípio incidir em situações de incerteza científica, é necessário que se tenha feito uma análise de risco tão completa quanto possível para medidas que possam ser tomadas (JANS; VEDDER, 2008, p. 39).

De modo geral, o princípio da precaução implica em que os atos que possam gerar dano grave e irreversível ao Meio Ambiente devam ser evitados até que sejam melhor analisados. Trata-se de uma obrigação de tomar medidas para proteger os humanos e o meio ambiente contra danos possíveis ou eventuais. Como bem pondera Aragão, não é irracional ou paralisador, mas um princípio racionalmente fundado, através do qual a humanidade assume sua responsabilidade com o futuro (2008, p. 14-15).

Portanto, é inegável o reconhecimento do princípio da precaução como peça chave para o desenvolvimento sustentável (BOSSELMANN, 2008, p. 60), tanto nos planos nacionais, com sua previsão em políticas públicas e leis locais, quanto no plano internacional, com convenções e tratados. A relação da precaução com a sustentabilidade é direta, uma vez que, evitando danos sérios e irreparáveis, protege-se o Meio Ambiente 
para as presentes e as futuras gerações.

A incidência do princípio da precaução depende de dois pressupostos: a existência de um risco relevante e a incerteza científica a respeito do mesmo (ARAGÃO, 2008; PEREZ, 2010). Tal incidência justifica a imposição de medidas que podem ser desde uma exigência de rotulagem até a proibição da atividade ou produto.

Aragão (2008, p. 21-23) pontua que os riscos que justificam a aplicação do princípio da precaução caracterizam-se por serem, globais, no sentido de que abrangem grandes regiões, em dimensões que anteriormente não eram atingidas pela atividade humana; retardados, porque decorrem da manutenção por longo tempo de determinada situação até que, depois de anos, décadas ou até mesmo séculos, levam a danos catastróficos por sua extensão. A irreversibilidade, ainda segundo a autora, é também uma característica dos riscos que justificam o princípio da precaução, pois suas consequências podem ser permanentes ou, pelo menos, irrecuperáveis no tempo de uma vida humana.

Estas características tornam os riscos graves, relevantes, (ARAGÃO, 2006, p. 26-32) na medida em que se tratam da possibilidade de danos de grande extensão, seja territorial, seja em termos populacionais, ou dos bens ambientais afetados, de grande complexidade, envolvendo processos que podem ter sido construídos por longo tempo e cuja duração pode ser bastante longa. A probabilidade do dano também compõe também o quadro de gravidade do risco, nesse sentido, quanto mais provável, mais relevante.

Perez (2010, p. 38-39) chama a atenção para o fato de que a irreversibilidade existe não só no que tange ao possível dano ambiental, mas também existe quando se decide preservar o meio ambiente, por exemplo, investindo dinheiro público que não estará disponível para outros objetivos públicos. Assim, ela pode não ser um critério capaz de estabelecer quando se deve utilizar uma medida de precaução ou não.

Além disso, afirma o autor que a própria noção de gravidade é imprecisa na medida em que pode ser avaliada de uma série de pontos de vista diferentes, tais como custos e justiça distributiva. Também pondera que não faria sentido interpretar o princípio da precaução como uma aversão genérica ao risco, porque não se pode evitar todo e qualquer risco, nem tampouco considerar graves apenas danos catastróficos porque não é este o uso dado ao princípio na prática (PEREZ, 2010, 39-40).

Com relação à incerteza científica a respeito do risco vale ressaltar que:

O princípio da precaução, por sua vez, disciplina duas situações bastante distintas entre si: as em que, embora as conseqüências do agir tecnológico sejam conhecidas, não é possível a atribuição de probabilidades objetivas a cada uma delas; e as em que não são conhecidas todas as consequiências do agir. À primeira situação corresponde a disciplina dos riscos potenciais, à segunda, a da ignorância. Em ambas as situações, o princípio da precaução preconiza a adoção de medidas tendentes a não gerar o dano (...) (SILVA, 2012).

Nesse sentido, há uma diferença importante com relação ao princípio da prevenção, porque, no caso deste último, não existe a incerteza, pois trata de situações nas quais existe conhecimento conclusivo de que determinada atividade ou produto gerará determinado dano (CARVALHO, 2013, loc. 1404-1405). 
A incerteza, de acordo com Aragão (2008, p. 33) pode se dar sobre: qual a causa de uma situação real e comprovada, se um fato em especial provocou um dano real ou ainda sobre a própria existência do dano. Refere a autora que, em especial no último caso, deve se analisar a verossimilhança da dúvida, sendo que, quanto mais grave o dano, menos é relevante a possibilidade de que ele ocorra para que se toma alguma medida de precaução. Perez (2010, p. 40-44), por outro lado, aduz que a incerteza é inerente ao conhecimento científico de modo que o critério de ausência de certeza não é adequado para definir a incidência ou não do princípio. Defende que a análise da incerteza justificadora de uma medida de precaução seja mais política do que científica.

Paulo Affonso Leme Machado (2007, p. 2-3) faz algumas considerações sobre os elementos psicossociais que envolvem o princípio da precaução, como a incerteza, a ignorância e o medo.

Afirma que a incerteza não é a total ausência de conhecimento. Pode ser o caso que o conhecimento não seja preciso, havendo, por exemplo, dúvidas sobre o que está por vir e sobre o modo de aplicação em determinado caso. Assim, ter algum conhecimento não equivale à certeza, pois essa se caracteriza pela total ausência de dúvida e de imprecisão, fato que nos leva à segurança. (MACHADO, 2007, p. 2)

Uma das formas de incerteza é a ignorância, que não pode ser um pretexto para a imprudência. $\mathrm{O}$ autor reforça que o objetivo do princípio da precaução não é paralisar o desenvolvimento, ou "conservar a ignorância", pelo contrário, quer vencê-la com pesquisas, estudos e avaliação de fatos e métodos. (MACHADO, 2007, p. 2)

O terceiro elemento psicossocial apontado é o medo. Afirma Machado (2007, p. 3 ) que, na concepção de Aristóteles, o medo funciona como receio de que algo aconteça, como uma expectativa do mal. Em certas circunstâncias, o medo pode confundir-se com escapismo ou fuga de responsabilidade. Entretanto, conclui que nem sempre é irrazoável ter medo, pois este pode aparecer de diversas formas, podendo ter um viés que resulta na responsabilidade. Este é o medo que se assemelha à prudência e à cautela. Neste sentido, o medo justifica-se, sendo adequado para conduzir a uma criteriosa avaliação dos projetos que devem ser seguidos.

Ainda, Lorenzetti (2010, p. 78) distingue a versão "Fraca", que trata o princípio da precaução como uma "declaração de natureza meramente exortativa e que é uma opção de política pública de aplicação voluntária” e a versão "Forte", que consiste na "norma jurídica que obriga a optar pela mais precavida das opções que se tenham à disposição".

Já Sunstein (2003, p. 1012), distingue entre o sentido fraco e o sentido forte. O sentido fraco do princípio da precaução foi o mais adotado nos ordenamentos jurídicos do mundo. Nessa versão, a dúvida sobre o acontecimento de danos futuros, é suficiente para a regulamentação da atividade. A Declaração do Rio, de 1992, segundo o autor, é exemplo que pode ser citado como o princípio da precaução no sentido fraco.

No sentido forte, o conceito e o alcance do princípio se tornam cada vez mais amplos. Na Europa, na opinião de tal autor, sobretudo pelas influências das teorias alemãs, a versão do princípio é ainda mais forte. Sugerem que é importante construir uma margem de segurança em cada decisão que é tomada, atribuindo o ônus vol.10, nº. 01, Rio de Janeiro, 2017.pp. 199-218 
da prova àquele que se propõe a realizar uma atividade possivelmente danosa. (SUNSTEIN, 2003, p. 1013)

Sunstein (2003, p. 1016-1017) afirma que a primeira versão é uma obviedade, ainda que seja necessária para evitar a procrastinação de providências necessárias. Considera o autor que é óbvio que o Estado deve regular situações em que existem relevante dúvidas sobre a possibilidade de danos, mas que os interesse envolvidos podem levar a postergação da tomada de medidas razoáveis. Deste modo, enunciar o princípio serve de diretriz para uma atuação responsável pelo poder público. No sentido forte, entretanto, segundo o mesmo autor, ao buscar uma situação de risco virtualmente zero, o princípio é paralisante, pois o risco está presente quando se age, mas também quando não se age (SUNSTEIN, 2003, p.1020-1021).

Kogan critica o princípio em especial na sua interpretação europeia afirmando que o mesmo se baseia em perigos hipotéticos "concebidos em um contexto de laboratório que pode ou não acontecer em algum momento em um incerto futuro distante, podem surgir em função de usos potenciais desconhecidos de produtos ou processos caracterizados a priori como inaceitáveis e inerentemente perigosos" (2007-2008, p. 495). Considera que tal concepção prejudica as condições dos países em desenvolvimento de tirar proveito de tecnologias capazes de proporcionar melhoras na qualidade de vida das pessoas (KOGAN, 2007-2008, p. 494496).

Não há, portanto, entendimento pacífico sobre as características do Princípio da Precaução, fato que dificulta a sua aplicação. No entanto, é inegável a necessidade de uma mudança quanto à responsabilidade que o ser humano possui sobre a natureza. Segundo O'Riordan as sociedades estão apenas começando a entender a importância da natureza no mundo (1994, p. 13). O autor expõe o fato de que as civilizações estão correndo contra o tempo, com o crescimento populacional e o consumo inapropriado dos recursos naturais.

O princípio da precaução é o que melhor orienta para que haja um esforço de toda a sociedade a fim de ter uma vida saudável na terra às presentes e futuras gerações. Somente precavendo as catástrofes e cuidando diariamente do meio ambiente é que podemos nos sensibilizar. (O’RIORDAN, 1994, p. 14).

O que este artigo pretende demonstrar é como a evolução do conceito do princípio da precaução, no sentido de assumir responsabilidades em situações de incerteza, é essencial para a proteção do meio ambiente.

Com as inovações científicas que ocorreram após a revolução industrial e se intensificaram nas últimas décadas, a sociedade se depara com diversos modos de aplicação das inovações tecnológicas. Há os que as desenvolvem pensando na sustentabilidade e no meio ambiente, bem como aqueles que se concentram no desenvolvimento por meio de políticas de consumo. Porém, o fato é que quanto mais possibilidades de inovação, maior a nossa responsabilidade sobre o meio ambiente. Nosso papel e a sobrevivência no mundo dependem do modo como asseguramos que as futuras gerações tenham condições de vida (COMEST, 2005, p. 17 - 20). Tratase de uma questão ética.

Nesse sentido, a UNESCO, na Comissão Mundial sobre a Ética no Conhecimento Científico e vol.10, nº. 01, Rio de Janeiro, 2017.pp. 199-218 
Tecnologia (World Commission on the Ethics of Scientific Knowledge and Technology - COMEST), propõe a aplicação do princípio da precaução como demanda ética à ciência e à tecnologia, para que todos os Estados Membros possam adaptar novos valores às suas escolhas. (COMEST, 2005).

A ética busca saber a ação correta e diz respeito a situações em que o ser humano pode escolher como agir. A responsabilidade ética depende da existência da liberdade de escolha (JONAS, 2006, p. 35-40 et passim). Então, a noção de que indivíduos são eticamente responsáveis por suas escolhas é a base do novo conceito do princípio da precaução (COMEST, 2005, p. 17-20).

Essa visão do princípio implica na mudança da responsabilidade pelos danos causados ao meio ambiente. Forma-se uma responsabilidade ética das pessoas para que elas tenham ciência das consequências das suas ações, independentemente de culpa. (COMEST, 2005, p. 21-50) Além disso, a concepção ética deve funcionar como um incentivo para que sejam feitas mais investigações sobre as consequências de cada ato realizado. Assim, se o desconhecimento ainda é grande, deve-se adiar a prática do ato, até que o conhecimento necessário seja alcançado (COMEST, 2005, p. 21 - 50).

O princípio da precaução como demanda ética resulta na necessidade de ações prudentes no avanço científico, a fim de evitar que sejam causados danos ao meio ambiente, bem como de assegurar o desenvolvimento de melhores técnicas e de incentivo às pesquisas e tecnologias, ou seja, assumir que o meio ambiente tem valor intrínseco para a sociedade. É necessária uma nova reflexão e análise sobre as éticas tradicionais, de modelo antropocêntrico e em que a natureza não é tida como uma responsabilidade humana. O modelo de ética de Kant, por exemplo, nega o extra-humano e se resolve pela ética da intenção, obedecendo à ação individual. Dirige-se ao imediato e ao plano individual (SETZER; GOUVEIA, 2008, p. 3). A responsabilidade de Hans Jonas, que é objeto deste artigo, explica a insuficiência dos imperativos éticos tradicionais diante das novas dimensões do agir coletivo. É necessário considerar a emergência de uma ética que garanta a existência humana e todas as formas de vida na biosfera.

Esta análise ética fornece bases para a densificação normativa do referido princípio, o qual, como se demonstrou, tem conteúdo indeterminado. Deste modo, as mencionadas ações prudentes podem tornar-se deveres jurídicos. Para tanto, no próximo capítulo do artigo será analisada ética da responsabilidade de Hans Jonas.

\section{A ÉTICA DA RESPONSABILIDADE DE HANS JONAS}

Em sua obra Princípio Responsabilidade, Hans Jonas (2006, p. 41-42) provoca o repensar da ética tradicional fundamentada no antropocentrismo, na relação "homem-homem", para uma nova concepção ética que engloba não só essa relação, mas também a do "homem-mundo", numa proposta de visão biocêntrica. 
A crítica à visão tradicional da ética se dá principalmente no que diz respeito a essa nova conexão entre a tecnologia e o homem. No passado, a técnica era absorvida como um meio para atingir a necessidade humana (mero instrumento), hoje passou a ser um fim em si mesmo, aliado ao progresso e satisfação pessoal (JONAS,2006, p. 43-44). Nesse sentido:

(...) a técnica deixa de ser pensada como uma coisa a ser perseguida visando a resolução de um problema, como instrumento, e passa a ser perseguida como um fim. A humanidade confere ao termo progresso algo como se fosse ligado a sua própria essência. (LIMA; RAMALHO; OLIVEIRA, 2014, p. 6-7)

Como causa dos reflexos dessa ética preponderantemente tradicional, o filósofo irá apresentar a necessidade de se questionar e reformular o imperativo categórico Kantiano, que salienta: "Devo portar-me sempre de modo que eu possa querer que a minha máxima se torne lei universal da natureza." (KANT, 2004, 402).

Segundo Jonas, o imperativo kantiano não é incompatível logicamente com a decisão de alguém que age sem se importar com o futuro da humanidade e que, portanto, não considera problemático que os outros façam o mesmo. Quando Kant propôs seu imperativo, que a conduta humana pudesse levar ao fim da humanidade não era uma possibilidade, hoje ela é. Hans Jonas (2006, p. 47-48), então, propõe um novo imperativo, adequado à mudança na natureza do agir humano, "Aja de modo a que os efeitos da tua ação sejam compatíveis com a permanência de uma autêntica vida humana sobre a Terra"; ou, expresso negativamente, "Aja de modo a que os efeitos da tua ação não sejam destrutivos para a possibilidade futura de uma tal vida”.

$\mathrm{O}$ atual estágio de desenvolvimento tecnológico torna necessário que os critérios éticos tomem em consideração o futuro distante e a cumulação de efeitos no tempo (JONAS, 2006, p. 78-79). Assim, ao contrário das formas éticas tradicionais para as quais "O bem e o mal, com o qual o agir tinha de se preocupar, evidenciam-se na ação, seja na própria práxis ou em seu alcance imediato, e não requeriam em planejamento de longo prazo" (JONAS, 2006, p. 35), a nova ética deve se responsabilizar pelo futuro. Nota-se o pensamento implícito de coletividade e de uma perspectiva futura, para essa nova proposta de agir, em sintonia com a concepção de responsabilidade total dirigida também aos governantes, conforme será visto a seguir.

A preocupação básica com a vida em todas as suas formas faz a ética voltar-se para as relações do homem com a natureza e o estudo de suas consequências, a fim de garantir a existência da vida humana futura na Terra. Hans Jonas (2006, p. 34) salienta que a natureza não pode ser vista mais como um simples instrumento para a satisfação dos fins humanos, já que ela própria apresenta seus fins e é merecedora de decorrentes das responsabilidades humanas. No passado, "A natureza, na concepção clássica de ética, não era objeto da responsabilidade humana; ela cuidava de si mesma". Isto porque ela era capaz de fazê-lo: o ser humano não tinha condições de destruí-la. Mas esse já não é mais o caso, pois a natureza está sujeita ao nosso poderio técnico 
científico.

Neste sentido, Jonas (2006, p. 48) não critica a ética tradicional em seu domínio e pretensão. Ele apenas afirma a sua insuficiência em função dos novos problemas que surgem do atual desenvolvimento tecnológico e científico. Em consonância com o cuidado em relação à natureza, ressalta como preocupação de sua nova percepção ética a existência humana em nosso planeta:

(...) o novo imperativo diz que podemos arriscar a nossa própria vida, mas não a da humanidade; (...) que nós não temos o direito de escolher a não existência de futuras gerações em função da existência da atual, ou mesmo de as colocar em risco. (JONAS, 2006, p. 48).

Visando fundamentar a sua teoria acerca do princípio responsabilidade, passamos a apresentar as categorias de pensamento filosófico que justificam essa nova ética.

A primeira categoria fundamentadora do princípio responsabilidade é a Heurística do Medo, que pode ser relacionada ao agir humano responsável frente à possibilidade de expectativa de não existência humana no futuro. (JONAS, 2006, p. 353) Dessa forma, verifica-se a necessidade de o homem agir com previsão em relação às consequências negativas de seus atos, mesmo que só prováveis ou possíveis. Nesse sentido, assevera o filósofo que "Em grandes causas, que atingem os fundamentos de todo empreendimento humano e são irreversíveis, na verdade não deveríamos arriscar nada" (JONAS, 2006, p. 77). O medo, nesse viés, se entende como prudência, motivo de cautela, ou seja, aquele que proporciona uma reflexão para um agir coerente, ciente de suas responsabilidades, que nos convida a agir de modo responsável. (JONAS, 2006, p. 351 - 353).

Assim, a heurística do medo se configura como a primeira obrigação da ética, que fará o ser humano agir com responsabilidade e refletir antes da prática de seus atos.

Uma segunda categoria para a base do princípio responsabilidade é a relação entre o Fim e o Valor. Nesse contexto, verifica-se a necessidade de reconhecer um fim para tudo que é existente no planeta e a possibilidade de se atribuir um valor a cada coisa. (JONAS, 2006, p. 143) Essa concepção retira a centralidade da importância do homem vivendo no hoje, e abre espaço para que se dimensione a importância do respeito na relação do homem com os seus semelhantes, hoje e amanhã, e também com a natureza como um todo (o mundo extra-humano), para a preservação da humanidade.

Hans Jonas demonstra que tudo que existe no universo, pelo simples fato de existir, possui e serve a um fim ao qual se destina, e que esse fim deve ser respeitado para um funcionamento harmônico da vida. Sobre essa concepção o filósofo argumenta:

Todo o órgão em um organismo serve a um fim, o qual ele realiza ao funcionar (...) o fato de que esse organismo tenha esse fim pode ser compreendido de diversas maneiras. $\mathrm{O}$ sentido mais neutro e menos controverso é aquele segundo o qual, em um organismo, tudo está disposto de modo tal que o efeito de cada parte contribui para manter o todo, assim como em uma máquina tudo está disposto de modo a contribuir para a sua função global (JONAS, 2006, p. 129).

Salientando a importância da natureza em relação ao agir humano, destaca que um dos seus fins vol.10, no. 01, Rio de Janeiro, 2017.pp. 199-218 
determinantes é a própria vida, pois, ao gera-la, a natureza, da qual o ser humano é parte, lhe apresenta como uma de suas principais finalidades. (JONAS, 2006, p. 139).

Como um terceiro fundamento do princípio responsabilidade tem-se o "Ser, o Dever e o Bem”.

Num primeiro momento, é demonstrada a primazia do Ser. O existir prevalece ao nada, porque no nada não há valor. Assim, o "ser" em todas as suas dimensões resulta de uma orientação no sentido de continuar sendo, existindo e, portanto, se opondo ao não ser. Assim responsabilidade é a exigência pertencente à realidade do ser, direcionada à preservação da vida. (JONAS, 2006, p. 102).

Por sua vez, a dimensão do "Dever" é vista como uma condição de impor a não preferência ao "não-ser", ou seja, o filósofo demonstra que em virtude da liberdade que o homem possui, ele deve ultrapassar a dimensão de ver no restante do mundo humano ou não-humano uma mera possibilidade de Ser com seus fins próprios, e passar a conceber essa possibilidade de visão em torno como uma obrigação, um Dever. Portanto:

Por meio da negociação do não-ser, o ser se torna um interesse positivo, ou seja, uma escolha permanente de si mesmo. Esse sim (ao Ser) que atua cegamente adquire uma força obrigatória em virtude da liberdade lúcida do homem. Ele (homem) precisa incorporar o sim (ao Ser) em sua vontade e impor ao seu poder, o 'não' ao não-ser. Mas essa transição do querer para o dever constitui o ponto crítico da teoria moral (JONAS, 2006, p. 152).

Sobre o Bem, Hans Jonas (2006, p. 149) considera que o Bem pertence à realidade do Ser, e se transforma em Dever a partir de uma vontade. Nesse viés o bem ou valor somente se tornam dever a partir de uma vontade capaz de realizá-lo. O filósofo ensina que o fazer o bem deve ser destinado a um fim, a uma causa, e não o bem de forma egoísta direcionado a si mesmo, pois isto estaria corroborando com a anterior ética tradicional, na satisfação pessoal e egoísta. Importante, o direcionamento do ato de fazer o bem como uma virtude. (JONAS, 2006, p. 156).

Fica estabelecida a conexão entre a prática do Bem e o sentimento de responsabilidade, indicando que é essa vontade transformadora do Bem no Dever que, ao interferir no nosso fundamento psicológico, irá repercutir no nosso sentimento moral de responsabilidade: "e é da própria essência da nossa natureza moral que a nossa intelecção nos transmita um apelo que encontre uma resposta em nosso sentimento. É o sentimento de Responsabilidade”. (JONAS, 2006, p. 157).

Por fim, na última dimensão de sua teoria ética é apresentada a fundamentação em relação à Responsabilidade Paterna, Política e a Responsabilidade Total.

Inicia o autor a fundamentação nesse ponto salientando que o que diferencia o ser humano frente aos demais seres é a capacidade de assumir responsabilidades para garantir seus próprios fins. Salienta o filósofo que:

Ser responsável efetivamente por alguém ou por qualquer coisa em certas circunstâncias (mesmo que não assuma e não reconheça tal responsabilidade) é tão inseparável da natureza do homem quanto o fato de que ele seja genericamente capaz de responsabilidade (JONAS, 2006, p. 175).

Essa responsabilidade genuína, inerente do ser humano, é evidenciada principalmente pela análise da 
responsabilidade paternal, ou seja, o cuidado dos pais com seus filhos a partir do nascimento. A responsabilidade paterna aos olhos de Hans Jonas, corresponde a um "dever implícito de forma muito concreta no ser", repercutindo como "obrigações objetivas sob a responsabilidade externa", e, portanto, de muito fácil constatação. (LIMA; RAMALHO; OLIVEIRA, 2014, p. 81).

Por outro lado, a Responsabilidade Política não seria resultado de uma relação incondicional e voltada para o individual, como a responsabilidade paterna. Essa responsabilidade é fruto de uma escolha de quem ambiciona o poder. Entretanto, a responsabilidade política, mesmo configurada na externalidade de um poder volta-se, para todos, objetivando o desenvolvimento social e em direções históricas (LIMA; RAMALHO; OLIVEIRA, 2014, p. 81).

Importa nessa parte da fundamentação é destacar a finalidade idêntica de ambas responsabilidades quando indicam para a conservação do fim primeiro do ser: a vida, como uma Responsabilidade Total. Conforme argumentos de Hans Jonas:

As assistências paterna e governamental não podem tirar férias, pois a vida do seu objeto segue em frente, renovando as demandas ininterruptamente. Mais importante é a continuidade dessa existência assistida como uma preocupação, que ambas as responsabilidades aqui analisadas necessitam considerar em cada oportunidade de atuação (JONAS, 2006, p. 185).

Dessa forma, devidamente evidenciadas as categorias fundamentadoras da teoria da ética da responsabilidade de Hans Jonas, em suas dimensões da "heurística do medo", do "fim e do valor", do "ser, dever e bem" e ainda na responsabilidade "total", há como avançar no intuito do presente artigo visando constatar a relação do princípio responsabilidade com o princípio da precaução.

\section{O PRINCÍPIO DA PRECAUÇÃO E A ÉTICA DA RESPONSABILIDADE}

Após as breves considerações do princípio da precaução e da ética de responsabilidade de Hans Jonas, a relação existente entre eles torna-se mais evidente.

O princípio responsabilidade nasce a partir da necessidade de mudança no agir do ser humano em frente a uma nova realidade tecnológica, refutando a ética tradicional antropocêntrica. Esse princípio está fundamentado na reflexão sobre a conduta humana e, principalmente, nas consequências que ela pode trazer para humanidade. A ética da responsabilidade, então, provoca o questionamento a respeito de como a civilização tecnológica atua, tendo como consequência a adoção do princípio da precaução.

Como visto, de acordo com Jonas, o valor da existência implica no dever de preservá-la, não assumindo riscos de danos sérios, ainda que improváveis, em função de benefícios que não estão fundados no valor do próprio ser.

Assim, Jonas (2006, p. 48) considera que o progresso técnico científico não deve ser visto como um fim vol.10, n. 01, Rio de Janeiro, 2017.pp. 199-218 
em si mesmo, mas como meio de realização do ser. Logo, quando a aventura tecnológica se contrapõe a sua própria finalidade, colocando em risco o futuro da humanidade, ela deixa de ser racional. Na própria reformulação do imperativo filosófico proposto pelo filósofo, fica evidenciada essa constante necessidade de pensar em relação ao futuro: "Aja de modo a que os efeitos da tua ação sejam compatíveis com a permanência de uma autêntica vida humana sobre a Terra".

Deste modo, se enfraquecem as críticas daqueles que se opõem a uma interpretação forte do princípio da precaução, em especial porque, com base no princípio responsabilidade, ele ganha a necessária densidade normativa. Vejam-se alguns exemplos:

Em primeiro lugar, se sempre existem riscos, como afirma Sustein, nem todos os riscos são iguais quando se tem por referência a manutenção de um futuro para a humanidade tal qual a conhecemos. É o risco de perdermos tudo que deve ser eliminado, se possível, e não qualquer risco.

Tal responsabilidade é mandamento irrecusável, não podendo ser mero elemento em um cálculo de perdas e danos. Não é mais razoável a mera ponderação entre eventuais consequências negativas futuras dos atos humanos em relação aos benefícios da inovação tecnológica que se apresenta. É necessário precaver-se de toda e qualquer possibilidade de perdas desastrosas, de proporções inimagináveis, em face da vida humana (JONAS, 2006, p. 80).

Essa reflexão do homem em seu agir com o mundo traduz o exercício da liberdade humana, de forma consciente, com a ocorrência da possibilidade de dizer não ao mundo. Assim, o fato do homem possuir responsabilidade deve ser consequência direta do seu exercício de liberdade. (JONAS, 2006, p. 144).

Deste modo, se "os grandes riscos da tecnologia não servem para abolir o mal extremo, mas para melhorar permanentemente o bem já alcançado, isto é, para o progresso, a renúncia a algumas de suas promessas diz respeito ao que excede o necessário" (JONAS, 2006, p. 85). O ser humano ao reconhecer as suas limitações deve escolher correr o risco de perder aquilo que não é tão importante, para proteger o que realmente importa.

Em segundo lugar, se de acordo com Kogan os riscos são resultado de um contexto de laboratório, considerando um futuro incerto e longínquo, a ética da responsabilidade exige justamente este tipo de construção na reflexão a respeito dos efeitos futuros da inovação. Nesse sentido, tal ética aponta para a inversão do princípio cartesiano da dúvida. Hans Jonas destaca que: "para tomarmos uma decisão deveríamos tratar como certo aquilo que é duvidoso, embora possível, desde que estejamos tratando de um determinado tipo de consequência" (JONAS, 2006, p. 87).

$\mathrm{Na}$ categoria da heurística do medo se pode encontrar uma conexão intensa com os fundamentos do princípio da precaução. $\mathrm{O}$ autor provoca uma reflexão sobre a análise dos riscos em relação ao agir humano. Com base no pensamento de precaução, a ética da responsabilidade, indicará o levantamento de todas as consequências prováveis ou possíveis, em busca de uma decisão objetivando afastar o maior risco possível. vol.10, no. 01, Rio de Janeiro, 2017.pp. 199-218 
Argumentos sobre as limitações do conhecimento dos atos científicos e tecnológicos ficam afastados, pois nada impede a projeção de efeitos finais prováveis ou apenas possíveis. Basta para que atrele à necessidade da precaução o mero saber sobre possibilidades de desastres ou danos graves (JONAS, 2006, p. 73 - 74).

É importante chamar a atenção ao fato de que no princípio da precaução está inserta a necessidade do saber, do conhecer para que possa dimensionar as consequências do ato a ser tomado, frente aos riscos prováveis ou possíveis.

Inclusive nesse aspecto verifica-se que a heurística do medo, conforme já mencionado, não irá impedir a ação, mas sim torná-la mais consciente, na medida em que se vai exigir o domínio sobre o estudo de suas consequenciais.

Logo, precaução e conhecimento (no sentido de saber), andam juntos, e a teoria de Jonas (2006, p. 64) vai ao encontro dos fundamentos do princípio da precaução, alertando para o sentido de cautela em relação ao fato de se desconhecer tudo que possa advir de uma ação. Segundo o autor o "próprio desconhecimento das consequências últimas é para uma contensão responsável a melhor alternativa, à falta da própria sabedoria".

Rompe-se, dessa forma, com a ética antropocentrista vigente, com o predomínio da satisfação individual (dentro de uma concepção utilitária), e que aponta somente para as consequências imediatas do agir humano. Provoca-se o pensar de forma diferenciada, almejando a projeção futura da vida do ser humano no planeta, a qual se tornou responsabilidade do mesmo em função do poderio por ele alcançado. (JONAS, 2006, p. 87).

Portanto, frente aos desafios que o progresso desenfreado da tecnologia e da ciência oferecem à civilização tecnológica, é necessária uma reflexão sobre a possibilidade de renúncia a algumas inovações, visando reformular um verdadeiro significado para os avanços científicos, como meios de obter uma melhora da condição de vida, não mais as considerando como fins em si mesmos.

Também nessa relação intrínseca entre a Ética Responsabilidade de Hans Jonas e o Princípio da Precaução, há de se destacar a fundamentação filosófica que a primeira pode dar ao Princípio, impulsionando-o rumo a uma concepção "forte" no sentido de normatização do dever de precaução, fortalecendo-o no mundo do direito. Em uma interpretação do princípio da precaução com base na ética da responsabilidade pode-se encontrar a referência de que a inovação tecnológica precisa passar a ser concebida, não mais como fim, mas na perspectiva do ser.

Nesse sentido, o desafio lançado por Jonas é ir além: do simples poder ou querer, ao dever (JONAS, 2006, 157). Para tanto, lógico se faz partir de uma concepção ética para verificar a possibilidade também de uma configuração jurídica desse dever, dando-lhe mais amplitude. Entra aqui o papel da importância da concepção de uma Responsabilidade Total, pertencente à quinta categoria estudada como fundamento da Teoria Responsabilidade de Hans Jonas.

A responsabilidade de Jonas alcança a sociedade como um todo, compreendendo os indivíduos e os vol.10, nº. 01, Rio de Janeiro, 2017.pp. 199-218 
governantes, que devem, em um primeiro momento buscar conhecimento e divulgar informação acerca dos possíveis riscos futuros de qualquer ação, de cunho tecnológico ou científico, que possa ser tomada pelo homem frente à natureza, em prol da preservação da vida (JONAS, 2006, p. 185).

O objetivo aqui, aliado à ideia da necessidade de conhecimento dentro da heurística do medo, é dar ciência à coletividade dos possíveis riscos de suas ações, evitando que somente sejam pretendidos "cegamente" benefícios de uma prática desenvolvimentista, benefícios esses imediatos e de cunho meramente "utilitarista". Com a consciência de tais efeitos futuros danosos, é que se provocará a atuação da sociedade através da prática de uma possível participação na implementação do princípio da precaução. A partir de então, a sociedade, democraticamente, escolhe seus representantes exigindo deles uma consciência e uma postura ambiental responsável, para que, em consequência das atividades dos mesmos, possam advir resultados de regulamentação normativa compatíveis com seus verdadeiros interesses.

Portanto, fundamental o papel da sociedade como um todo, principalmente através dos instrumentos da educação e da informação, para a divulgação de uma ética de responsabilidade madura sobre o meio ambiente e o futuro da existência do homem na Terra. Em consequência dessa conscientização, embasa-se uma concepção forte do Princípio da Precaução, (LORENZETTI, 2010, p. 78) através de sua regulamentação nas instituições internas ou internacionais. Busca-se, assim, pelo princípio da precaução em seu sentido "forte", não só o bem individual, mas o bem do outro e o da coletividade, com base em exigências morais. (JONAS, 2006, p. 156).

Outro fundamento do princípio da precaução que merece atenção, com fundamento na filosofia de Hans Jonas, é o aspecto temporal no tocante à regulamentação da atividade humana.

O primeiro passo que se deve dar para compreensão dessa relação de tempo a uma prática efetiva do Princípio da Precaução deve ser o entendimento da concepção de medo segundo os ensinamentos de Hans Jonas. A concepção clara de medo, alinhada ao princípio da precaução, como já visto, deve ser entendida como consequência de trazer para o presente à possibilidade de risco futuro, antecipando a percepção dos riscos possíveis, e provocando o efeito de paralisação que o medo traz em um primeiro momento. (MACHADO, 2007, p.3). O medo, em condições normais, no que tange ao agir, não significa necessariamente uma paralisação em nossas ações por tomar conhecimento dos riscos, também nos impulsiona a um imediato reagir frente à situação apresentada. Logo, através dessa antecipação dos possíveis efeitos futuros indesejáveis, pela concepção da heurística do medo apresentada por Hans Jonas, haverá a repercussão de um agir diferenciado do homem frente a tais circunstâncias.

Sobre esse aspecto alerta que a antecipação das consequências de um ato serve para que se examinem as mesmas consequências no momento da decisão de agir ou não agir, o que irá repercutir no grau de responsabilidade que o ato irá gerar:

E mesmo a antecipação das consequências ao iniciar um ato não serve como motivo para vol.10, nº. 01, Rio de Janeiro, 2017.pp. 199-218 
agir, mas como mecanismo de seleção, ou seja, como motivo para permitir ou suspender a execução do ato. Enfim, quanto menos se age, menor é a nossa responsabilidade, e, na ausência de um dever positivo, evitar a ação pode constituir uma recomendação de prudência (JONAS, 2006, p. 166).

Logo, tal agir humano, além de ser proveniente de sua natureza moral, deve se fortalecer na esfera do direito, proporcionando uma concepção "forte" do princípio da precaução, ou seja, passando de uma mera e futura possibilidade de atuação para uma efetiva exigência de ação imediata, com a análise de todos os riscos, e também dando ênfase, frente aos riscos de maior potencial, do surgimento de uma obrigação de natureza "de fazer" ou "de não fazer", pela coletividade (COMEST, 2005).

A concepção temporal no estudo de Hans Jonas se visualiza, também, como condição essencial quando o mesmo afirma que o homem em suas ações deverá considerar o presente, mas também junto desse tempo, o cuidado com o futuro da vida humana.

Nesse sentido, aplica-se um dever, reflexo não só da ética, como também deve ser do mundo do direito, fortalecendo o princípio da precaução, de preservação da existência da humanidade futura, independentemente do fato de que nossos descendentes diretos estejam entre ela; e também um dever em relação ao seu modo de ser, à sua condição, que deve nos liberar para uma reflexão (JONAS, 2006, p. 90). Assim, ainda sobre esse aspecto do princípio da precaução em relação à continuidade futura da vida na Terra, o filósofo menciona que outro desafio de uma ética da responsabilidade é incluir a noção de futuro na análise dos atos presentes (JONAS, 2006, p. 186). Assim, não se deve agir apenas após a ocorrência do dano, como se faz no âmbito da responsabilidade civil tradicional. Se, no futuro, pode haver danos graves, o direito deve instrumentalizar uma atuação de precaução.

Trata-se da proteção de direitos, que além de coletivos, possuem sujeitos ainda indefinidos, que virão a existir. Quem poderá sofrer os prejuízos dos atos não permitidos normativamente são sujeitos futuros, tanto humanos, como não humanos. Nesse sentido, a consideração do futuro, no Brasil, tem base constitucional, já que o art. 225 de nossa Carta Magna afirma o dever de preservar o meio ambiente para as presentes e futuras gerações.

Vale dizer, com base em Carvalho (2013, loc. 4703-4704), que em nosso direito positivo há também um fundamento dogmático mais específico para esta consideração do futuro. O art. 187 do Código Civil estabelece que: "Também comete ato ilícito o titular de um direito que, ao exercê-lo, excede manifestamente os limites impostos pelo seu fim econômico ou social, pela boa-fé ou pelos bons costumes”. Como aponta o referido autor, tal dispositivo não menciona a necessidade de dano atual para a ocorrência da ilicitude. Na medida, então que uma inovação de maneira contraditória com a sua finalidade coloca em risco bens de altíssima relevância, ela passa a ser ilícita exigindo medidas que evitem tais riscos. Conforme Carvalho (2013, loc. 5404) tais medidas se configurariam em obrigações de fazer ou não fazer, as quais estão abarcadas no objeto da ação civil pública (Lei no 7.347/85), e não necessitam de aplicação apenas após a ocorrência do dano.

Ainda Carvalho (2013, loc. 4737), de maneira coerente com que se discutiu sobre a teoria de Jonas, 
afirma que:

(...) a ponderação do que excede manifestamente os limites socioambientais da atividade econômica não consiste tarefa fácil, devendo haver uma racionalização das incertezas inerentes ao futuro, a partir da aplicação reflexiva do binômio probabilidade (da ocorrência futura do evento lesivo ambiental) e magnitude (gravidade ou irreversibilidade em caso de concretização futura).

Verificam-se, assim, como as considerações sobre o futuro podem aparecer em uma discussão jurídica específica, não se tratando de "meras" especulações filosóficas.

Dessa forma, portanto, fundamentando-se em aspectos da heurística do medo, do ser e seu desafio em repercutir em dever e da responsabilidade total de Hans Jonas, o princípio da precaução vai rompendo às críticas de configurar-se na sua concepção "forte" e adquirindo robustez para um maior impacto e uma intensa atuação no mundo do direito.

\section{CONSIDERAÇÕES FINAIS}

O presente artigo se propôs a apresentar o princípio da precaução sob uma concepção ética, que se relaciona com o princípio responsabilidade de Hans Jonas, diante de uma reflexão sobre os valores impostos pelas sociedades contemporâneas, e fundamentando-o frente às críticas atuais e a sua inserção com maior impacto no mundo jurídico.

$\mathrm{Na}$ fase tecnológica atual, as civilizações devem desenvolver suas concepções éticas, para tomar como responsabilidade a presença do ser humano na Terra. Segundo Hans Jonas, certas transformações nas nossas capacidades acarretaram mudanças na natureza do agir humano e, a transformação do agir humano também impõe uma modificação ética. Os riscos graves, que põe em risco a existência da humanidade, advindos da civilização tecnológica, devem receber um enfoque especial para o exercício da precaução.

Propõe-se a natureza, pertencente ao mundo "não-humano", não mais como um mero instrumento. Ela tem um fim em si mesmo, que repercute na finalidade única da continuidade da vida, e, portanto, torna-se merecedora de cuidado e reflexos desse novo agir acautelado. Para que o princípio da precaução seja entendido como responsabilidade ética, é necessário romper com a ética antropocêntrica vigente, que aponta somente para as consequências imediatas e de cunho individualista do agir humano.

$\mathrm{Na}$ teoria acerca do princípio responsabilidade, Jonas demonstra algumas categorias de pensamento filosóficas que justificam essa nova ética. Mas é com base nas categorias do Ser e do Dever, na Responsabilidade Total e na Heurística do medo, principalmente nessa última, que se pode encontrar uma conexão intensa com os fundamentos do princípio da precaução.

Há uma evolução do princípio da precaução no sentido de que devemos agir conscientes das consequências dos atos praticados e, inclusive, deixar de agir quando houver possibilidade de que as 
consequências sejam desastrosas não só para quem pratica o ato, como para toda a existência da humanidade futura e também de sua relação com a biosfera.

O autor provoca uma reflexão sobre a análise dos riscos em relação ao agir humano. Se devemos tratar como certo aquilo que é duvidoso, para efeito de danos graves, então é necessário que exista precaução em um sentido forte. $\mathrm{O}$ agir humano deve ser fundamentado com conhecimentos e estudos suficientes, que garantam a responsabilidade sobre cada ato.

Portanto, a ética e os valores de uma sociedade são o cerne do agir humano, que resulta na efetividade, ou não, do princípio da precaução. A concepção ética e individualista de Kant, deve ser superada para dar sentido à coletividade estar inserida na natureza, visando a preservação da vida humana na Terra.

E mais ainda, é necessário dar ao princípio da precaução efetivamente sua dimensão "forte" de concepção, passando de uma simples possibilidade de observância, para uma obrigatoriedade com força jurídica, ampliando sua densidade normativa interna e internacional.

Os modelos éticos tradicionais assumidos na contemporaneidade ainda têm uma dimensão particular de curto prazo do dever e do bem, sem refletir sobre a coletividade e as futuras gerações. Assim, o principal desafio da ética da responsabilidade é incluir a noção de responsabilidade tanto em relação ao agir sob a observância moral, como também em relação ao mundo do direito.

Portanto, nesse novo viés de responsabilidade, o agir implica em refletir, ponderar e afastar riscos possíveis. A ética sugerida pela teoria de Hans Jonas apresenta-se como orientação de um agir de forma responsável, consciente e sustentável, em estreita relação como Princípio da Precaução, que cada vez mais deve se fortalece no cenário interno e internacional.

Na medida em que o Princípio da Precaução ganha dimensão ética e ele se densifica normativamente e não se torna sujeito às críticas de imprecisão conceitual e incerteza científica, eis que a proteção do futuro da humanidade e da vida exclui opções interpretativas contraditórias a este objetivo.

Impõe-se a necessidade urgente de refletir sobre quais são as prioridades da humanidade, e alertar para a compreensão do ser humano como mais um ser vivo existente na Terra, inerente à natureza, participante de um todo, e a partir de então, como responsável pela sua própria existência e das suas gerações futuras.

\section{THE PRECAUTIONARY PRINCIPLE AND HANS JONAS' RESPONSIBILITY PRINCIPLE}

\section{Abstract}

The article has the purpose to show that Hans Jonas's concept of responsibility can justify the precautionary principle. The human being's role is to ensure and secure life conditions for the present and future human vol.10, nº. 01, Rio de Janeiro, 2017.pp. 199-218 
generations and also all types of life on Earth. The precautionary principle, as an ethical and legal demand, requires adaptingvalues and moral views of society in this sense. The essay expose the need to rethink the precautionary principle in accordance with the new view of responsability. To achieve this goal, it starts with qualitative and theoretical studie about the precautionary principle and Hans Jonas's works. The theoretical reference is the author's work: "The Imperative of Responsibility: in search of ethics for the technological age", writen by the end of century XX. The essay takes us to the conclusion that Hans Jonas goes further than the subjectivism of the moral values and make us rethink about responsibility of humanity towards the Earth. The precautionary principle is seen as a guide to the responsible, conscious and sustainable acts. Thus, there is a possibility of a connection between the precautionary principle and the philosophical bases of ethics and moral presented.

Keywords: Precaution; Environment; Sustainability; Responsability; Ethics.

\section{REFERÊNCIAS BIBLIOGRÁFICAS}

ARAGÃO, A. Princípio da precaução: manual de instruções. CEDOUA, v. 2, p. 9-57, 2008. Disponível em: <http://hdl.handle.net/10316.2/8833>. Acesso em : 25 ago. 2016.

BOSSELMANN, K. The Principle of Sustainability: transforming law and governance. Auckland: Ashgate Publishing Limited, 2008.

CARVALHO, Délton Winter de. Dano ambiental futuro: a responsabilidade civil pelo risco ambiental. 2. ed. rev., atual. e ampl. Porto Alegre: Livraria do Advogado, 2013.

COMEST. The Precautionary Principle. Disponível em: $<$ http://unesdoc.unesco.org/images/0013/001395/139578e.pdf>. Acesso em : 19 set. 2016.

CONFERÊNCIA DAS NAÇÕES UNIDAS SOBRE O MEIO AMBIENTE. Declaração do Rio 92. Disponível em: <http://www.onu.org.br/rio20/img/2012/01/rio92.pdf>. Acesso em : 19 ago. 2016.

JANS, J. H; VEDDER, H. H.B. European Environmental Law, 3a ed. Groningen: Europa Law Publishing, 2008.

JONAS, H. O Princípio Responsabilidade: ensaio de uma ética para uma civilização tecnológica. Rio de Janeiro: PUC RIO, 2006.

KANT, E. Crítica da Razão Prática. São Paulo: EbooksBrasil, 2004. Disponível em: <http://www.ebooksbrasil.org/eLibris/razaopratica.html>. Acesso em : 10 mai. 2016

KOGAN, Lawrence A. The Extra-Wto Precautionary Principle: One European "Fashion" Export the United States can do without. Temp. Pol. \& Civ. Rts. L. Rev. 17, 2007-2008. p.491-604.

LIMA, A. C. DE; RAMALHO, Â. M. C.; OLIVEIRA, S. S. F. DE. Hans Jonas e a Ética da Responsabilidade: um novo imperativo para ações ecologicamente sustentáveis. Qualit@s Revista Eletrônica, v. 16 n. 2, 2014.

LORENZETTI, R. L. Teoria Geral do Direito Ambiental. São Paulo: Revista dos tribunais, 2010.

MACHADO, P. A. L. M. O Princípio da Precaução e a Avaliação dos Riscos. Revista dos Tribunais, v. 856, p. 1 - 
$37,2007$.

MICHAELIS. Precaução: Significado de "precaução" no Dicionário Português Online: Moderno Dicionário da Língua Portuguesa - Michaelis - UOL. Disponível em: <http://michaelis.uol.com.br/moderno/portugues/index.php?lingua=portugues-

portugues\&palavra=precau\%E7\%E3o $>$. Acesso em : 18 mai. 2016.

MILARÉ, E. Direito do Ambiente. A Gestão Ambiental em Foco. 6a Ed. ed. São Paulo: [s.n.], 2009.

O'RIORDAN, T. Interpreting the Precautionary Principle. London: Earthscan, 1994. Disponível em: <https://books.google.com/books?hl=pt-BR\&lr=\&id=9qp878BOw_MC\&pgis=1 >. Acesso em : 15 ago. 2016.

PEREZ, Oren. Precautionary Governance and the Limits of Scientific Knowledge: A Democratic Framework for Regulating Nanotechnology. UCLA J. Envtl. L. \& Pol'y. vol. 28. 2010. p. 29-76.

SETZER, J.; GOUVEIA, N. DA C. Princípio da precaução rima com ação. Revista dos Tribunais, v. 49/2008, p. $158-183,2008$.

SILVA, Renato Pereira e. Biossegurança e princípio da precaução. Capturado em http://www.oab.org.br/revistacndh/anexos/BIOSSEGURANCA_E_PRINCIPIO_DA_PRECAUCAO.pdf. Acesso em: 21 fev. 2012.

SUNSTEIN, C. R. Beyond the Precautionary Principle. University of Pennsylvania Law Review, v. 151, n. n. 3, p. 1003-1058, 2003. Disponível em: <http://www.jstor.org/stable/3312884?seq=1\#page_scan_tab_contents>. Acesso em : 09 set. 2016.

Trabalho enviado em 24 de junho de 2016.

Aceito em 06 de outubro de 2016. 